\title{
Corrosion Propagation Behavior of low-Cr steel Rebars in Simulated Concrete Environments
}

\author{
Ming Liu ${ }^{1,2, *}$, Xuequn Cheng ${ }^{3, *}$, Xiaogang $\mathrm{Li}^{3,4}$ \\ ${ }^{1}$ MOE Key Laboratory for Multifunctional Materials and Structures, Xi'an Jiaotong University, Xi'an \\ 710049, PR China \\ ${ }^{2}$ State Key Laboratory for Mechanical Structure Strength and Vibration, Xi'an Jiaotong University, Xi'an \\ 710049, PR China \\ ${ }^{3}$ Corrosion and Protection Center, University of Science and Technology Beijing, Beijing 100083, PR \\ China \\ ${ }^{4}$ Ningbo Institute of Material Technology \& Engineering, Chinese Academy of Sciences, Ningbo \\ 315201, Zhejiang, PR China \\ *E-mail: liuming0313@xjtu.edu.cn (Ming Liu), chengxuequn@ustb.edu.cn (Xuequn Cheng)
}

doi: $10.20964 / 2019.01 .55$

Received: 8 September 2018 / Accepted: 7 November 2018 / Published: 30 November 2018

Corrosion propagation behavior of HRB400 carbon steel and three low- $\mathrm{Cr}$ steel rebars in alkaline solution simulating concrete pore solution were studied using potentiostatic /galvanostatic polarization, and wire beam electrode (WBE) measurement. Results show that the radial corrosion process of the steels are controlled by ohm resistance and the propagation time can be calculated by $r=k t^{1 / 3}$. The corrosion propagation process of the steels are inhibited when the electrode potential is below $-0.6 \mathrm{~V}$ (vs. SCE). The corrosion areas of HRB400 steel is widespread and $\mathrm{Cr}$-modified steels are relatively limited, $\mathrm{Cr}$-modified steels have higher pitting corrosion factors. With the increasing of $\mathrm{Cr}$ content, the pitting corrosion factor of the steel increases, and the corresponding localized corrosion anode length decreases. $5 \mathrm{Cr}$ steel has the longest corrosion propagation time which is about 16.7 years, $3 \mathrm{Cr}$ steel is 10.3 years, $1.5 \mathrm{Cr}$ steel is 5.4 years, and $\mathrm{HRB} 400$ steel is only 3.6 years. Using $\mathrm{Cr}-$ modified steels can prolong the corrosion propagation period of concrete structures, and $5 \mathrm{Cr}$ steel shows the best.

Keywords: low-Cr steel; Polarization; WBE; Pitting; Service life

\section{FULL TEXT}

(C) 2019 The Authors. Published by ESG (www.electrochemsci.org). This article is an open access article distributed under the terms and conditions of the Creative Commons Attribution license (http://creativecommons.org/licenses/by/4.0/). 